\title{
The short-term effect of dark chocolate flavanols on cognition in older adults: A randomized controlled trial (FlaSeCo)
}

\section{Suominen, M.H.}

2020-07-15

Suominen , M H , Laaksonen , M M L , Salmenius-Suominen , H , Kautiainen , H , Hongisto , S-M , Tuukkanen , K , Jyväkorpi , S K \& Pitkälä , K H 2020 , ' The short-term effect of dark chocolate flavanols on cognition in older adults: A randomized controlled trial (FlaSeCo) ', Experimental Gerontology , vol. 136 , 110933 . https://doi.org/10.1016/j.exger.2020.110933

http://hdl.handle.net/10138/328417

https://doi.org/10.1016/j.exger.2020.110933

cc_by_nc_nd

acceptedVersion

Downloaded from Helda, University of Helsinki institutional repository.

This is an electronic reprint of the original article.

This reprint may differ from the original in pagination and typographic detail.

Please cite the original version. 


\section{Journal Pre-proof}

The short-term effect of dark chocolate flavanols on cognition in older adults: A randomized controlled trial (FlaSeCo)

M.H. Suominen, M.M.L. Laaksonen, H. Salmenius-Suominen, H. Kautiainen, S.-M. Hongisto, K. Tuukkanen, S.K. Jyväkorpi, K.H. Pitkälä

PII: $\quad$ S0531-5565(20)30051-6

DOI: $\quad$ https://doi.org/10.1016/j.exger.2020.110933

Reference: $\quad$ EXG 110933

To appear in: $\quad$ Experimental Gerontology

Received date: $\quad$ 19 January 2020

Revised date: $\quad 5$ March 2020

Accepted date: $\quad 22$ March 2020

Please cite this article as: M.H. Suominen, M.M.L. Laaksonen, H. Salmenius-Suominen, et al., The short-term effect of dark chocolate flavanols on cognition in older adults: A randomized controlled trial (FlaSeCo), Experimental Gerontology (2018), https://doi.org/ 10.1016/j.exger.2020.110933

This is a PDF file of an article that has undergone enhancements after acceptance, such as the addition of a cover page and metadata, and formatting for readability, but it is not yet the definitive version of record. This version will undergo additional copyediting, typesetting and review before it is published in its final form, but we are providing this version to give early visibility of the article. Please note that, during the production process, errors may be discovered which could affect the content, and all legal disclaimers that apply to the journal pertain.

(C) 2018 Published by Elsevier. 
The short-term effect of dark chocolate flavanols on cognition in older adults: a randomized controlled trial (FlaSeCo)

Suominen MH, Laaksonen MML, Salmenius-Suominen H, Kautiainen H, Hongisto S-M, Tuukkanen K, Jyväkorpi SK, Pitkälä KH

Suominen MH, Department of General Practice and Primary Health Care, University of Helsinki, Finland and Society for Gerontological Nutrition in Finland Laaksonen MML, Fazer Group Research, Finland

Salmenius-Suominen H, Department of General Practice and Primary Health Care, University of Helsinki, Finland and Society for Gerontological Nutrition in Finland

Kautiainen H, Department of General Practice and Primary Health Care, University of Helsinki Hongisto S-M, Fazer Group Research, Finland

Tuukkanen K, Fazer Group Research, Finland

Jyväkorpi SK, Department of General Practice and Primary Health Care, University of Helsinki Pitkälä KH, Department of General Practice and Primary Health Care, University of Helsinki

\section{Corresponding author:}

Merja Suominen

email: merja.suominen@gery.fi

Postal address: Malmin kauppatie 26, 00700 Helsinki 
Background: Cocoa flavanols in the diet have had positive effects on cognition, blood lipid levels, and glucose metabolism.

Methods: Cognitively healthy older adults aged 65-75 years were recruited for an eight-week randomized, double-blind controlled trial to investigate the effectiveness of cocoa flavanols on cognitive functions. At baseline, nutrient and polyphenol intakes from diet were assessed with three-day food diaries. The intervention group received $50 \mathrm{~g}$ dark chocolate containing $410 \mathrm{mg}$ of flavanols per day, and the control group $50 \mathrm{~g}$ dark chocolate containing $86 \mathrm{mg}$ of flavanols per day, for eight weeks. Cognition was assessed with Verbal Fluency (VF) and the Trail Making Test (TMT) A and B as the main outcome measures. Changes in blood lipids and glucose were also measured.

Results: The older adults participating numbered 100 (63\% women), mean 69 y (range 65 to 74 ). They were highly educated with a mean 14.9 years of education (SD 3.6). No differences in changes in cognition were seen between groups. The mean change ( \pm SEs $)$ in the time to complete the TMT A and B in the intervention group was $-4.6 \mathrm{~s}(-7.1$ to -2.1$)$ and $-16.1 \mathrm{~s}(-29.1$ to -3.1$)$, and in the controls $-4.4 \mathrm{~s}(-7.0$ to -1.9$)$ and $-12.5 \mathrm{~s}(-22.8$ to -2.1$)$ (TMT A p=0.93; TMT B p=0.66). No difference was apparent in the changes in blood lipids, glucose levels, or body weight between the groups.

Conclusions: The healthy older adults showed no effect from the eight-week intake of dark chocolate flavanols on cognition.

Keywords: Cocoa flavanols; Chocolate; Cognition; Aging 


\section{Introduction}

Diets high in polyphenols have been associated with a lower risk of cognitive decline (Lamport et al. 2014). Cocoa is a rich source of polyphenols, especially the flavanols epicatechin and catechin (Willams et al. 2012, Żyżelewicz et al. 2016). Regular consumption of cocoa flavanols may reduce blood pressure, improve insulin sensitivity, reduce fat oxidation, and induce vasodilation, thus increasing blood flow in the brain, which is essential for optimal brain function (Grassi et al. 2005, Grassi et al. 2008, Sorond et al. 2013, Lamport et al. 2014, Dower et al. 2015). Similarly, epidemiological studies show that cocoa consumption has been associated with better cognition and decreased Alzheimer disease (AD) risk (Commenges et al. 2000, Crichton et al. 2016). Moreover, flavonoid and other polyphenol-rich foods have been able to improve some cognitive domains in short-time trials (Nooyens et al. 2011, Kean et al. 2015, Alharbi et al. 2016, Kent et al. 2017, Miller et al. 2018).

The antioxidant effects of flavonoids, including cocoa flavanols, were first proposed to explain their beneficial effects on cognitive functions (Rice-Evans et al. 2001). The main cocoa flavanol epicatechin can increase the bioavailability of nitric oxide, the main regulator of vascular function, leading to improvements in vascular tone and blood pressure regulation (Socci et al. 2017). Moreover, cocoa flavanols may have independent neuromodulatory and neuroprotective actions, and they apparently accumulate in the hippocampus, which is responsible for learning and memory (Sokolov et al. 2013).

In recent years, an increasing amount of evidence supports the role of cocoa-derived product and chocolate consumption in the neurocognitive and neuroprotective enhancement of executive functions, attention, and memory, particularly among subjects with cognitive decline (Socci et al. 2017). In a cross-sectional study with community-dwelling adults, high dark chocolate consumption 
was associated with better cognitive function, including very old people, and the relationship was not attenuated when adjusted for cardiovascular, lifestyle, and dietary factors (Crichton et al. 2016). The few intervention studies on cocoa flavanol intake and cognitive performance have shown mixed results. Short-term studies among healthy middle-aged or older adults showed cognitive benefits from cocoa flavanol consumption in cocoa drinks or supplements (Camfield et al. 2012, Brickman et al. 2014, Mastroiacovo et al. 2015, Neshatdoust et al. 2016 ). Similar results have been found for older people with high blood pressure (Sorond et al. 2013) and older people with mild cognitive impairment (Desideri et al. 2012), whereas one study among healthy older participants consuming dark chocolate together with a cocoa drink showed a null result (Crews et al. 2008). The trials conducted have, however, mostly been small, and the cognitive domains were measured in very heterogenic ways (Lamport et al. 2014). It is unknown whether the cocoa flavanol in commercially available dark chocolate has cognitive benefits for healthy older people.

The aim of our study was to clarify the effect of an eight-week intake of commercially available dark chocolate with high flavanol content, especially the epicatechin content, on cognition among healthy older participants, 65-75-year-old men and women. The setting was a double-blind, randomized, controlled trial using chocolate with reduced flavanol content as a control. In addition, we assessed the changes in blood glucose, lipids, and body mass index. 


\section{Subjects and methods}

\subsection{Participants}

The participants were recruited in the capital area of Finland mainly through a public release that was sent to the press and radio channels. In the release the nature of the research and the main inclusion and exclusion criteria were described. The inclusion criteria included cognitively healthy adults aged 65-75 years without diagnosed, chronic diseases, whose BMI was less than 32 (in $\mathrm{kg} / \mathrm{m}^{2}$ ) without a major weight change during the past year, who did not smoke, and who were willing to sign the informed consent. Exclusion criteria were medication for blood pressure and high cholesterol, current smokers, habitual users of antioxidant supplements, and daily consumers of chocolate or other cocoa products. Before taking any other measurements from them, the participants completed the SLUMS test (Tariq et al. 2006) to ensure that they had normal cognition. Those whose result was less than 27 points (high school education) or less than 25 (less than high school) were excluded.

Figure 1. Recruitment of the subjects.

A total of 439 subjects responded to the press release and showed interest in the study by contacting us by phone, email, or an internet-based registration form. Altogether 313 were excluded in the telephone screening, 142 due to their medical history, refusal to provide information or another reason for not fulfilling the inclusion criteria, and 171 respondents were excluded after the statistical power calculation. Based on the telephone screening, 126 persons attended the baseline visit, and their blood was sampled for the metabolic parameters (fP-Gluc, fS-Chol, fS-Chol-HDL, fS-Chol-LDL, fS-Trigly, fS-Crea, S-ALAT, S-GT, S-K, S-Na, S-Uraat). Based on the results of the laboratory analysis and the evaluation of the study geriatrician (KP), 22 subjects were excluded due 
to high total cholesterol $(n=11,>7.0 \mathrm{mmol} / \mathrm{l})$, cognitive decline $(\mathrm{n}=5)$, high liver value $(\mathrm{n}=4, \mathrm{~S}$ ALAT>43.0 U/l, S-GT>133.0 U/l), acute illness $(n=1)$, and refusal $(n=1)$. The final number in our study was 104 subjects, who were randomized into intervention and control groups. In both groups two subjects dropped out and did not give us permission to use their data. The final number of participants was 100 (Figure 1).

The Ethics Committee of the Helsinki University Central Hospital and that of the research committee of the Social Insurance Institution of Finland approved the study. This trial was registered in ACTRN 12617000748314.

\subsection{Study design and outcomes}

To evaluate the effect of the daily consumption of dark chocolate on cognitive performance in healthy older subjects, an eight-week randomized, double-blind, parallel-arm study was conducted from August 2017 to December 2017. The main outcome measures were Verbal Fluency (VF) from CERAD (Consortium to Establish a Registry for Alzheimer's Disease), (Morris et al. 1989) and Trail Making Test A and B (TMT; Lezak et al. 1998).

At the baseline visit the participants gave blood samples, and their cognition was evaluated with the VF and TMT tests. A nutritionist (HSS) instructed them to keep three-day food diaries, and the participants received guidance on how to include dark chocolate in their daily diet and keep their energy intake in balance. The participants were instructed to substitute their sweet snacks with the reference or intervention chocolate, and they were told to limit the intake of polyphenol-rich food items, such as wild berries and apples, which are usually consumed in autumn time in Finland, and tea, red wine, fruit and vegetable juices, and chocolate other than the research chocolate. All of the participants received leaflets on how to follow an overall healthy and balanced diet. All of the participants were also instructed to continue their usual lifestyle habits. 
Before the randomization as soon as the laboratory results were ready, the participants with an abnormal metabolic and cognitive profile were excluded. At the second visit, the participants returned their food diaries, and they were randomized into intervention and control groups. The participants received chocolate pralines with a white or silver paper cover on them, representing the blinded intervention and control groups. The pralines were divided into daily portions of 50 grams (seven pralines). All of the pralines for the eight-week intervention were given at the same time.

The intervention group received $50 \mathrm{~g}$ dark chocolate per day containing $410 \mathrm{mg}$ total of flavanols, of which $85 \mathrm{mg}$ was epicatechin, and the control group received $50 \mathrm{~g}$ dark chocolate per day with $86 \mathrm{mg}$ total of flavanols per day, of which $26 \mathrm{mg}$ was epicatechin. The intervention chocolate was commercially available dark chocolate (Karl Fazer 70\% Dark Chocolate Pralines). The reference chocolate with low flavanol content was produced especially for the study purposes using higher processing temperatures and a longer conching time with highly processed cocoa powder. The intervention chocolate was higher in fibre, potassium, magnesium, and zinc and lower in sucrose compared to the reference chocolate. Table 1 describes the contents of the chocolates.

Procyanidins were determined in Natural Resources Institute Finland (LUKE) according to Robbins et al. (2013). Briefly, procyanidins were extracted from defatted samples with acidified aqueous acetone. The extracts were purified with Strata SCX SPE (Phenomenex Inc., Torrance, CA, USA) cartridges and filtered into the HPLC vials. Agilent 1290 Infinity (Agilent Technologies Inc., Santa Clara, CA, USA) equipped with fluorescence detection (FLD; $\lambda$ ex $=275 \mathrm{~nm}, \lambda e \mathrm{~m}=324 \mathrm{~nm}$ ) was used for HPLC analyses. Procyanidins were separated according to their degree of polymerization (DP) on a Luna Diol HILIC (Phenomenex Inc., Torrance, CA, USA) column $(150 \times 4.6 \mathrm{~mm}, 3 \mu \mathrm{m})$ at temperature $35^{\circ} \mathrm{C}$. The mobile phase was a binary gradient (solvents $\mathrm{A}$ and $\mathrm{B}$ ) consisting of acetonitrile-acetic acid $(98+2, A)$ and methanol-water-acetic acid $(95+3+2$, B). Elution was started with $3 \%$ of $B$, followed by a linear gradient to $50 \%$ of B in $25 \mathrm{~min}$, to $100 \%$ in $28 \mathrm{~min}$, 
isocratically for $2 \mathrm{~min}$ and back to the starting point in $3 \mathrm{~min}$. Flow rate was $1 \mathrm{~mL} / \mathrm{min}$ and injection volume $4 \mu \mathrm{L}$. The post time was 5 min before next injection. Quantification was based on an external standard of (-)-epicatechin (Sigma-Aldrich Inc., St Louis, MO, USA). Procyanidins with different DPs were quantified according to their relative response factors (in relation to (-)epicatechin) given by Robbins et al. (2013). Each sample was analyzed in triplicate. 
Table 1. Nutritional values of the intervention and reference chocolates.

\begin{tabular}{|c|c|c|}
\hline Nutrients (100 g) & Reference chocolate & Intervention chocolate \\
\hline Energy $(\mathrm{kcal} / \mathrm{kJ})^{1}$ & $558 / 2336$ & $562 / 2353$ \\
\hline Total fat $(\mathrm{g})^{2}$ & 35.3 & 40 \\
\hline Saturated fatty acids $(\mathrm{g})^{3}$ & 21.5 & 24.7 \\
\hline Monounsaturated fatty acids $(\mathrm{g})^{3}$ & 11.2 & 12.3 \\
\hline Polyunsaturated fatty acids $(\mathrm{g})^{3}$ & 1 & 1.1 \\
\hline Carbohydrates $(\mathrm{g})^{1}$ & 53.7 & 37.2 \\
\hline Sucrose $(g)^{4}$ & 52.2 & 29.7 \\
\hline Non-soluble fibre $(\mathrm{g})^{5}$ & 3.9 & 7.9 \\
\hline Soluble fibre $(\mathrm{g})^{5}$ & 1 & 1.7 \\
\hline Potassium (mg) 6 & 600 & 840 \\
\hline 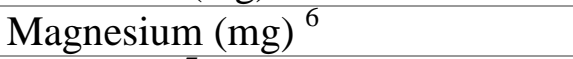 & 84 & 170 \\
\hline Zinc $(\mathrm{mg})^{7}$ & 1.3 & 2.8 \\
\hline Total flavanols (mg) & 172 & 820 \\
\hline Epicatechin (mg) & 52 & 170 \\
\hline
\end{tabular}

1 Method: (EU) No 1169/2011, Eurofins Food \& Feed Testing, Linköping, Sweden

2 Method: 2009/152/EU mod., Eurofins Food \& Feed Testing, Linköping, Sweden

3 Method: Internal Method - GC-FID, GC-FID, Eurofins Food \& Feed Testing, Linköping, Sweden

4 Method: AOAC 982.14, mod., Eurofins Food \& Feed Testing, Linköping, Sweden

5 Method: Internal Method: Enzymatic-gravimetry, Eurofins Food Testing Netherlands,

Heerenveen, Netherlands

6 Method: DIN EN ISO 11885, mod., Eurofins WEJ Contaminants GmbH, Hamburg, Germany

7 Method: DIN EN ISO 17294-2-E29, mod., Eurofins WEJ Contaminants GmbH, Hamburg,

Germany

The three-day food diaries and other measurements were collected prior to randomization. The average daily energy and nutrient intake were calculated based on the food diaries.

\subsection{Measurements}


The baseline measurements included demographic data, diagnoses, and medication. The diagnoses and medications were confirmed based on written medical records and prescriptions provided by the participants. We also assessed the participants' cognition with the Saint Louis University Mental Status (SLUMS) Exam (Tariq et al. 2006) to confirm the subjects' capability of participating in the intervention.

At baseline and follow-up, we measured the participants' weight and height and calculated their body mass index (BMI). We measured weight with a portable and calibrated scale, and height with a standardized measure against the wall. We used the equation weight $(\mathrm{kg}) / \mathrm{height}(\mathrm{m})^{2}$ to calculate BMI.

The Trail Making Test (TMT) A and B (Lezak et al. 1998) and Verbal Fluency (VF) (Morris et al. 1989) were used to assess the change in cognition during the intervention. The TMT is a neuropsychological test of visual attention and task switching. It consists of two parts in which the subject is instructed to connect a set of 25 dots as quickly as possible while still maintaining accuracy. A lower number of seconds indicates better performance. The test can provide information about mental flexibility, processing speed, and executive functioning. In the VF test, the participant produces as many animal words as possible in 60 seconds. A higher number of animals indicates better performance. A good performance in VF indicates mental flexibility and cognitive productivity (Sotaniemi et al. 2012).

We used the three-day food diaries to assess food and nutrient intake. During the first visit the nutritionist gave written and verbal instructions to the participants on how to keep the food diaries. She also gave the participants $100 \mathrm{~mL}, 15 \mathrm{~mL}$, and $5 \mathrm{~mL}$ measuring cups for measuring food items such as drinks and bread spreads. The participants were instructed to complete the food diaries over a period of three days including one weekend day while maintaining their usual diet. Participants brought the completed diaries to the nutritionist, and she checked their entries. Common things 
checked by the nutritionist were the types of milk and fat used, and the trademarks of the food items or the amounts of food. Energy, protein, and nutrient intake were calculated using the AIVO-diet nutrition program (https://www.mashie.com/fi/palvelut/ravintolaskenta/).

Blood samples were drawn from the participants after an overnight fasting period at the beginning and the end of the trial. We used a laboratory package to ensure that the participants' health condition was stable and adequate for this intervention. The participants' fasting plasma glucose, cholesterols (total, HDL, and LDL), triglycerides, haemoglobin (B-Hb, E-MCHC, E-MCH), erythrocytes (B-HKR, E-MCV), leucocytes, platelets, creatinine, alanine aminotransferase, and glutamyl transferase were determined. In addition, we wanted to explore whether the intervention had an effect on the laboratory values.

\subsection{Sample size}

Sample size calculation was based on the Trail Making Test (TMT A). It was assumed that a minimum group difference would be $20 \%$ in the points of the TMT A with a type I error of $5 \%$, statistical power of $80 \%$, and $20 \%$ of drop outs in the groups, which resulted in 50 participants per group (Mastroiacovo et al. 2015).

\subsection{Randomization}

The participants who met all the inclusion criteria and had sufficient cognitive performance $(\mathrm{n}=$ 104) were randomly allocated to the intervention $(n=52)$ and control $(n=52)$ groups according to a computer-generated randomization list. Four participants dropped out and refused permission to use their data, resulting in 50 in the intervention and 50 in the control group.

\subsection{Blinding}


The intervention was double-blinded. Neither the researchers nor participants were aware of the treatment allocation. The chocolate pralines were wrapped with a white or silver paper cover representing the blinded intervention and control groups. The code was revealed after the intervention was finished.

\subsection{Statistical methods}

Data are presented as means with standard deviation (SD) or as counts (n) with percentages (\%). Statistical comparison between the groups was performed by t-test. The method (achieved significance level) was used when the theoretical distribution of the test statistics was unknown or in the case of a violation of the assumptions (e.g. non-normality). Effect size (d) for the intervention was calculated by using Cohen's method where an effect size of 0.20 is considered small, 0.50 moderate, and 0.80 large. CIs for the effect sizes were obtained by bias-corrected bootstrapping (5000 replications). The normality of the variables was tested by using the Shapiro-Wilk W test. The Stata 15.1, StataCorp LP (College Station, TX, USA) statistical package was used for the analysis.

\section{Results}

\subsection{Baseline}

The number of participants was 100 (63\% women), and their mean age was 69 years (SD 2.5). The mean BMI of the participants in the whole group was $25.0 \mathrm{~kg} / \mathrm{m}^{2}$ (SD 3.6). They had a mean education of 14.9 years (SD 3.6), and their HRQoL was good. The mean level of blood glucose was $5.0 \mathrm{mmol} / \mathrm{l}(\mathrm{SD} \mathrm{0.4)}$ and total cholesterol $5.6 \mathrm{mmol} / \mathrm{l}$ (SD 0.7). 
The groups were similar at baseline. The baseline characteristics in the intervention and reference groups appear in Table 2. 
Table 2. Background characteristics, lifestyle factors, and metabolic and cognitive parameters at baseline.

\begin{tabular}{|c|c|c|}
\hline & $\begin{array}{l}\text { Reference group } \\
\text { Low-flavanol chocolate } \\
\qquad \mathrm{N}=50\end{array}$ & $\begin{array}{l}\text { Intervention group } \\
\text { High-flavanol chocolate } \\
\qquad \mathrm{N}=50\end{array}$ \\
\hline Women, n (\%) & $30(60)$ & $31(62)$ \\
\hline Age, mean (SD) & $68(3)$ & $69(2)$ \\
\hline Years of education, mean (SD) & $14.9(3.8)$ & $14.4(3.0)$ \\
\hline Cohabiting, $\mathrm{n}(\%)$ & $27(54)$ & $29(58)$ \\
\hline SLUMS, mean (SD) & $27.8(1.4)$ & $28.0(1.2)$ \\
\hline \multicolumn{3}{|l|}{ Dietary intake, mean (SD) } \\
\hline Energy $(\mathrm{kJ})$ & $7564(1650)$ & $8228(2109)$ \\
\hline Energy (kcal) & $1807(394)$ & $1965(504)$ \\
\hline Total fat $(\mathrm{g})$ & $79.9(26.2)$ & $89.0(33.3)$ \\
\hline Saturated fat (g) & $28.2(10.7)$ & $31.9(14.3)$ \\
\hline Protein $(\mathrm{g})$ & $72.9(20.9)$ & $81.5(25.3)$ \\
\hline Carbohydrates (g) & $221(49)$ & $232(61)$ \\
\hline Sucrose $(\mathrm{g})$ & $84.9(28.2)$ & $85.2(30.0)$ \\
\hline Fibre $(\mathrm{g})$ & $23.4(8.1)$ & $24.7(10.4)$ \\
\hline Salt (mg) & $7310(2914)$ & $7418(2343)$ \\
\hline Vitamin D $(\mu \mathrm{g})$ & $8.89(4.95)$ & $9.76(6.80)$ \\
\hline Folate $(\mu \mathrm{g})$ & $276(138)$ & $287(100)$ \\
\hline Potassium (mg) & $3741(875)$ & $3787(1105)$ \\
\hline Calcium (mg) & $978(332)$ & $1024(386)$ \\
\hline Clinical parameters, mean (SD) & 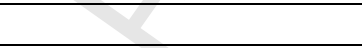 & \\
\hline BMI $\left(\mathrm{kg} / \mathrm{m}^{2}\right)$ & $24.3(3.6)$ & $25.4(3.5)$ \\
\hline \multicolumn{3}{|l|}{ Waist circumference $(\mathrm{cm})$} \\
\hline Women & $83(11)$ & $86(11)$ \\
\hline Men & $94(8)$ & $96(9)$ \\
\hline GDS & $1.8(3.0)$ & $2.3(3.6)$ \\
\hline Laboratory parameters, mean (SD) & 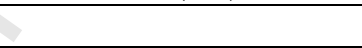 & \\
\hline Fasting plasma glucose $(\mathrm{mmol} / \mathrm{L})$ & $4.93(0.29)$ & $5.00(0.45)$ \\
\hline Total cholesterol $(\mathrm{mmol} / \mathrm{L})$ & $5.60(0.74)$ & $5.66(0.63)$ \\
\hline LDL cholesterol (mmol/L) & $3.42(0.56)$ & $3.37(0.55)$ \\
\hline HDL cholesterol (mmol/L) & $1.73(0.44)$ & $1.84(0.47)$ \\
\hline Total triglycerides $(\mathrm{mmol} / \mathrm{L})$ & $1.02(0.29)$ & $1.00(0.39)$ \\
\hline
\end{tabular}

\subsection{Intervention}

In the intervention group the participants ate $94 \%$ of the offered chocolate, whereas in the control group they ate $98 \%$ of their chocolate. 
No differences were seen in changes in cognition between groups. The mean change (95\% CI) in the time to complete TMT A and B in the intervention group was $-4.6 \mathrm{~s}(-7.1$ to -2.1$)$ and $-16.1 \mathrm{~s}(-$ 29.1 to-3.1), and in the controls $-4.4 \mathrm{~s}(-7.0$ to -1.9$)$ and $-12.5 \mathrm{~s}(-22.8$ to -2.1$)$ (Table 3$)$.

Table 3. Changes in cognitive parameters during the intervention.

\begin{tabular}{|c|c|c|c|c|c|c|}
\hline & \multicolumn{2}{|c|}{ Baseline } & \multicolumn{2}{|c|}{ Change from baseline } & \multirow{2}{*}{$\begin{array}{c}\mathrm{P}- \\
\text { value }\end{array}$} & \multirow{2}{*}{$\begin{array}{c}\text { Effect Size* } \\
(95 \% \mathrm{CI})\end{array}$} \\
\hline & $\begin{array}{l}\text { Reference } \\
\mathrm{N}=50 \\
\text { Mean } \\
\text { (SD) }\end{array}$ & $\begin{array}{l}\text { Intervention } \\
\qquad \mathrm{N}=50 \\
\text { Mean (SD) }\end{array}$ & $\begin{array}{c}\text { Reference } \\
\mathrm{N}=50 \\
\text { Mean }(95 \% \mathrm{CI})\end{array}$ & $\begin{array}{c}\text { Intervention } \\
\mathrm{N}=50 \\
\text { Mean }(95 \% \mathrm{CI})\end{array}$ & & \\
\hline Trail Making Test, $\mathrm{s}$ & & & & 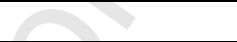 & & \\
\hline A & $\begin{array}{c}41.0 \\
(10.4)\end{array}$ & $41.1(10.3)$ & $\begin{array}{c}-4.4(-7.0 \text { to }- \\
1.9)\end{array}$ & $\begin{array}{c}-4.6(-7.1 \text { to }- \\
2.1)\end{array}$ & 0.93 & $\begin{array}{c}0.02(-0.37 \text { to } \\
0.41)\end{array}$ \\
\hline $\mathrm{B}$ & $\begin{array}{c}91.1 \\
(41.8)\end{array}$ & $95.3(44.4)$ & $\begin{array}{c}-12.5(-22.8 \text { to }- \\
2.1)\end{array}$ & $\begin{array}{c}-16.1(-29.1 \text { to }- \\
3.1)\end{array}$ & 0.66 & $\begin{array}{c}0.09(-0.31 \text { to } \\
0.48)\end{array}$ \\
\hline $\begin{array}{l}\text { Verbal Fluency test, } \\
\text { words } / 60 \mathrm{~s}\end{array}$ & $23.0(4.9)$ & $23.6(5.5)$ & $2.8(1.4$ to 4.3$)$ & $3.0(1.6$ to 4.3$)$ & 0.90 & $\begin{array}{c}0.02(-0.37 \text { to } \\
0.42)\end{array}$ \\
\hline SLUMS & $27.8(1.4)$ & $28.0(1.2)$ & $1.1(0.6$ to 1.6$)$ & $1.3(0.8$ to 1.6$)$ & 0.59 & $\begin{array}{c}0.11(-0.29 \text { to } \\
0.50)\end{array}$ \\
\hline Cerad & $14.2(1.1)$ & $13.8(1.0)$ & $0.3(0.1$ to 0.6$)$ & $0.5(0.2$ to 0.8$)$ & 0.35 & $\begin{array}{c}0.19(0.21 \text { to }- \\
0.58)\end{array}$ \\
\hline
\end{tabular}

*Effect size (d) was calculated by using the Cohen's method where an effect size of 0.20 is considered small, 0.50 moderate, and 0.80 large. Cls for the effect sizes were obtained by bias-corrected bootstrapping (5000 replications).

No differences were seen in the changes of metabolic parameters during the intervention between the intervention and control groups (Table 4.).

Table 4. Changes in metabolic parameters during the intervention.

\begin{tabular}{|l|c|c|c|c|c|}
\hline & \multicolumn{2}{|c|}{ Baseline } & \multicolumn{2}{|c|}{ Change from baseline } & P-value \\
\hline & $\begin{array}{c}\text { Control } \\
\mathrm{N}=50 \\
\text { Mean (SD) } \\
\text { Wean (SD) }\end{array}$ & $\begin{array}{c}\text { Intervention } \\
\text { N=50 } \\
\text { Meigth, Kg }\end{array}$ & $\begin{array}{c}\text { Control } \\
\text { Mean }(95 \% \\
\mathrm{CI})\end{array}$ & $\begin{array}{c}\text { Intervention } \\
\mathrm{N}=50 \\
\text { Mean }(95 \% \\
\mathrm{CI})\end{array}$ & \\
\hline $\begin{array}{l}\text { Fasting plasma glucose } \\
\text { (mmol/L) }\end{array}$ & $70.0(12.9)$ & $73.4(12.3)$ & $0.6(0.3$ to 0.9$)$ & $\begin{array}{c}0.3(0.0 \text { to } \\
0.7)\end{array}$ & 0.20 \\
\hline $\begin{array}{l}\text { Total cholesterol } \\
\text { (mmol/L) }\end{array}$ & $5.60(0.74)$ & $5.66(0.63)$ & $\begin{array}{c}-0.01(-0.14 \text { to } \\
0.11)\end{array}$ & $\begin{array}{c}-0.01(-0.14 \\
\text { to } 0.12)\end{array}$ & 0.93 \\
\hline
\end{tabular}




\begin{tabular}{|l|c|c|c|c|c|}
\hline $\begin{array}{l}\text { LDL cholesterol } \\
(\mathrm{mmol} / \mathrm{L})\end{array}$ & $3.42(0.56)$ & $3.37(0.55)$ & $\begin{array}{c}-0.07(-0.20 \text { to } \\
0.05)\end{array}$ & $\begin{array}{c}-0.05(-0.15 \\
\text { to } 0.06)\end{array}$ & 0.75 \\
\hline $\begin{array}{l}\text { HDL cholesterol } \\
(\mathrm{mmol} / \mathrm{L})\end{array}$ & $1.73(0.44)$ & $1.84(0.47)$ & $\begin{array}{c}0.01(-0.04 \text { to } \\
0.06)\end{array}$ & $\begin{array}{c}0.00(-0.05 \\
\text { to } 0.06)\end{array}$ & 0.88 \\
\hline $\begin{array}{l}\text { Total triglycerides } \\
(\mathrm{mmol} / \mathrm{L})\end{array}$ & $1.02(0.29)$ & $1.00(0.39)$ & $\begin{array}{c}0.07(-0.02 \text { to } \\
0.16)\end{array}$ & $\begin{array}{c}0.08(-0.02 \\
\text { to } 0.18)\end{array}$ & 0.87 \\
\hline
\end{tabular}

\section{Discussion}

Daily consumption of 50 grams of dark chocolate with high flavanol content for eight weeks did not influence the cognitive parameters that were studied among healthy participants aged 65-75 years in this double-blind, placebo-controlled, randomized trial. In addition, no differences were seen in the changes in the intervention and control participants' weight or blood glucose and lipid levels. The compliance with the chocolate intake was excellent in both groups. This is one of the few randomized double-blind controlled trials studying the effects of dark chocolate that is naturally high in cocoa flavanols on the cognitive functions of cognitively healthy older people.

The heterogeneity of a study design that studies the effects of cocoa flavanols on cognitive functions is a major challenge. Yet only a few trials have examined the effects of cocoa flavanol intake on cognitive functions in middle-aged or older adults (Crews et al. 2008, Camfield et al. 2012, Desideri et al.2012, Sorond et al. 2013, Brickman et al. 2014, Mastroiacovo et al. 2015, Neshatdoust et al. 2016). In addition to our study, Crews et al. (2008) is the only trial investigating the effects of dark chocolate naturally high in cocoa flavanols on cognitive functions. Crews et al. (2008) studied the effects of 60\% dark chocolate bars (37 g, $397 \mathrm{mg}$ flavanols) and cocoa beverage (237 ml, $357 \mathrm{mg}$ flavanols) on neuropsychologic functions and cardiovascular health among healthy subjects over 60 years of age in a six-week intervention. Our results are in line with their findings, which did not support the predicted beneficial effects of short-term dark chocolate consumption on 
cognitive functions or cardiovascular health. The amount of cocoa flavanols in the study by Crews et al. (2008) was almost double compared to the dose in our trial (410 $\mathrm{mg} / 50 \mathrm{~g}$ daily dose of dark chocolate).

In most trials, cocoa flavanols have been consumed as drinks (Desideri et al. 2012, Sorond et al. 2013, Mastroiacovo et al. 2015, Neshatdoust et al. 2016) or as part of a diet that includes supplements (Brickman et al. 2014), and only one previous study included a dark chocolate bar in addition to a cocoa drink (Crews et al. 2008). The intervention chocolate in this trial was commercially available dark chocolate naturally high in cocoa flavanols (410 mg/daily portion), which is close to the daily dose $(494-520 \mathrm{mg}$ ) that has been proven effective in previous trials (Desideri et al. 2012, Mastroiacovo et al. 2015, Neshatdoust et al. 2016). The type and bioavailability of cocoa flavanols may differ in enriched products such as drinks (Desideri et al. 2012, Sorond et al. 2013. Mastroiacovo et al. 2015, Neshatdoust et al. 2016) and supplements (Brickman et al. 2014) compared to dark chocolate naturally high in cocoa flavanols (Crews et al. 2008), which may have affected the results. Further studies should compare the neurocognitive effects of different types of products containing cocoa flavanols.

In previous trials, the participants' age, health and cognitive status, and educational level have been heterogeneous. A few trials have included healthy middle-aged and older adults (Camfield et al. 2102, Brickman et al. 2014, Mastroiacovo et al. 2015, Neshatdoust et al. 2016), another studied subjects with mild cognitive impairment (Desideri et al. 2012), and one study examined participants with vascular risk factors (Sorond et al. 2013). Our participants were 65-75 years of age, and at this age the decline in cognitive performance begins to show in tests. However, the participants in this study had a healthy cognitive status and metabolic profile compared to the population of the same age group (Koponen et al. 2018, FinHealth 2017 Study). Furthermore, their dietary intake at 
baseline met the recommendations well (Valsta et al. 2018, FinDiet 2017 Study). In addition, the education level of the subjects was high with a mean over 14 years of education, and at baseline they performed cognitive tests with excellent results. Higher educational levels compared with lower levels have been associated with a greater cognitive reserve and result in better performance in cognitive tests (Lezak et al. 2004). These facts may have caused a ceiling effect on the cognition outcome parameters.

Some previous studies in different age groups have shown favourable effects of cocoa flavanols on the parameters of cardiovascular health such as LDL- and HDL-cholesterol levels, flow-mediated dilatation, and insulin resistance; however, the results are conflicting (Hooper et al. 2012). The latest trials with a higher cocoa flavanol dose in drinks compared to the dose in dark chocolate in our trial have shown positive effects on metabolic profile (Desideri et al. 2012. Mastroiacovo et al. 2015). In our trial, we did not find any differences in weight, lipid profile, or fasting glucose levels between the baseline and end of the intervention, suggesting that dark chocolate is a safe source of cocoa flavanols for healthy older adults.

We chose the Trail Making Test (TMT) and Verbal Flow test as the main outcome measures based on the latest scientific knowledge (Morris et al. 1989, Lezak et al. 1998) because the combination of these tests is feasible for this kind of trial and the most sensitive for measuring changes in intervention among older adults (Lezak et al. 2004). The same cognitive measurements have also been used in previous trials (Desideri et al. 2012, Sorond et al. 2013, Mastroiacovo et al. 2015). The cognitive tests have evaluated the indirect association between cocoa flavanol intake and cognitive performance but do not provide information on the direct mechanisms of action of cocoa flavanols. Two potential explanations are improvements in the cerebral blood volume or an increase in serum BDNF (brain-derived neurotrophic factor) concentration (Brickman et al. 2014, Neshatdoust et al. 
2016). A recent meta-analysis found that patients with Alzheimer's disease, but not mild cognitive impairment, have significantly lower serum BDNF levels compared to healthy controls $(\mathrm{Ng}$ et al. 2019). Future research should include modern neuroimaging techniques that enable measuring the changes in neuromodulatory properties such as brain signalling activity, neurogenesis, and blood flow (Sokolov et al. 2013). Functional near infrared spectroscopy (fNIRS) is a novel method which measures the cortical blood flow or hemodynamics (Ho CS et al 2016). fNIRS can be used to assess cognitive impairment and neuropsychiatric disorder (Ho CS et al 2018). As depression was found to be associated with cardiovascular risk factors (Ho RC et al 2018) and regular consumption of cocoa flavanols may reduce cardiovascular risk factors. Further research is required to assess the potential benefits on hemodynamics and depression in older adults (Husain et al 2019).

The strength of our study is the study design of a randomized, double-blind, and controlled trial using commercially available dark chocolate naturally high in cocoa flavanols and dark chocolate with low flavanol content as a reference. The recruitment process was very fluent due to the high interest in an intervention concerning chocolate. The compliance with consuming the daily dark chocolate portion was high, and the drop-out level was very low. The limitations of our study are the small sample size and high educational level and cognitive status compared to the average in the same age group. Thus, the cognitive outcomes may have had a ceiling effect. The participants might have been a selected group of people that are especially interested in their health and nutrition.

\section{Conclusions}

In conclusion, the short-term use of dark chocolate naturally high in flavanols showed no benefit in the studied cognitive parameters in cognitively healthy older adults.

\section{References}


Lamport DJ, Saunders C, Butler LT, Spencer JP. Fruits, vegetables, 100\% juices, and cognitive function. Nutr Rev 2014;72:774-789. doi: 10.1111/nure.12149.

Williams RJ, Spencer JP. Flavonoids, cognition, and dementia: actions, mechanisms, and potential therapeutic utility for Alzheimer disease. Free Radic Biol Med 2012;52:35-45. doi: 10.1016/j.freeradbiomed.2011.09.010.

Żyżelewicz D, Krysiak W, Oracz J, Sosnowska D, Budryn G, Nebesny E. The influence of the roasting process conditions on the polyphenol content in cocoa beans, nibs and chocolates. Food Research International 2016; 89: 918-929. doi.org/10.1016/j.foodres.2016.03.026

Grassi D, Necozione S, Lippi C, Croce G, Valeri L, Pasqualetti P et al. Cocoa reduces blood pressure and insulin resistance and improves endothelium-dependent vasodilation in hypertensives. Hypertension 2005; 46:398-405. doi: 10.1161/01.HYP.0000174990.46027.70

Grassi D, Desideri G, Necozione S, Lippi C, Casale R, Properzi G. et al. Blood pressure is reduced and insulin sensitivity increased in glucose-intolerant, hypertensive subjects after 15 days of consuming high-polyphenol dark chocolate. J Nutr 2008;138:1671-6. doi: 10.1093/jn/138.9.1671

Sorond FA, Hurwitz S, Salat DH, Greve DN, Fisher ND. Neurovascular coupling, cerebral white matter integrity, and response to cocoa in older people. Neurology 2013; 81:904-9. doi: 10.1212/WNL.0b013e3182a351aa

Dower JI, Geleijnse JM, Gijsbers L, Zock PL, Kromhout D, Hollman PC. Effects of the pure flavonoids epicatechin and quercetin on vascular function and cardiometabolic health: a 
randomized, double-blind, placebo-controlled, crossover trial. Am J Clin Nutr 2015;101: 914-921. doi: 10.3945/ajen.114.098590

Commenges D, Scotet V, Renaud S, Jacqmin-Gadda H, Barberger-Gateau P, Dartigues JF. Intake of flavonoids and risk of dementia. Eur J Epidemiol 2000;16:357-63. doi:

10.1023/A:1007614613771

Crichton GE, Elias MF, Alkerwi A. Chocolate intake is associated with better cognitive function: the Maine-Syracuse Longitudinal Study. Appetite 2016;100:126-32. doi:

10.1016/j.appet.2016.02.010

Nooyens ACJ, Bueno-de-Mesquitra HB, van Bostel MPJ, et al. Fruit and vegetable intake and cognitive decline in middle-aged men and women: the Doetinchem Cohort Study. Br J Nutr 2011;106:752-61. doi: 10.1017/S0007114511001024

Kean RJ, Lamport DJ, Dodd GF, Freeman JE, Williams CM, Ellis JA, Butler LT, Spencer JP. Chronic consumption of flavanone-rich orange juice is associated with cognitive benefits: an 8-wk. randomized, double-blind, placebo-controlled trial in healthy older adults. Am J Clin Nutr 2015;101(3):506-14. doi: 10.3945/ajen.114.088518

Alharbi MH, Lamport DJ, Dodd GF, Saunders C et al. Flavonoid-rich orange juice is associated with acute improvements in cognitive function in healthy middle-aged males. Eur J Nutr 2016;55(6):2021-9. doi: 10.1007/s00394-015-1016-9 
Kent K, Charlton K, Roodenrys S, Batterham M, Potter J, Traynor V, Gilbert H, Morgan O, Richards R. Consumption of anthocyanin-rich cherry juice for 12 weeks improves memory and cognition in older adults with mild-to-moderate dementia. Eur J Nutr 2017;56:333-41. doi: 10.1007/s00394-015-1083-y

Miller MG, Hamilton DA, Joseph JA, Shukitt-Hale B. Dietary blueberry improves cognition among older adults in a randomized, double-blind, placebo-controlled trial. Eur J Nutr 2018;57:1169-80. doi: 10.1007/s00394-017-1400-8

Rice-Evans C. Flavonoid antioxidants. Curr Med Chem 2001;8(7):797-807. doi: $10.2174 / 0929867013373011$

Socci V, Tempesta D, Desideri G, Gennaro L, Ferrara M. Enhancing Human Cognition with Cocoa Flavonoids. Front Nutr 2017;4:19. doi: 10.3389/fnut.2017.00019

Sokolov AN, Pavlova MA, Klosterhalfen S, Enck S. Chocolate and the brain: neurobiological impact of cocoa flavanols on cognition and behavior. Neurosci Biobehav Rev 2013; 37:2445-53. doi: 10.1016/j.neubiorev.2013.06.013

Camfield DA, Scholey A, Pipingas A, Silberstein R, Kras M, Nolidin K et al. Steady state visually evoked potential (SSVEP) topography changes associated with cocoa flavanol consumption. Physiol Behav 2012;105:948-57. doi: 10.1016/j.physbeh.2011.11.013 
Brickman AM, Khan UA, Provenzano FA, Yeung LK, Suzuki W, Schroeter H et al. Enhancing dentate gyrus function with dietary flavanols improves cognition in older adults. Nat Neurosci 2014;17:1798-803. doi: 10.1038/nn.3850

Mastroiacovo D, Kwik-Uribe C, Grassi D, Necozione S, Raffaele A, Pistacchio L et al. Cocoa flavanol consumption improves cognitive function. blood pressure control. and metabolic profile in elderly subjects: the Cocoa. Cognition and Aging (CoCoA) Study—a randomized controlled trial. Am J Clin Nutr 2015;101:538-48. doi: 10.3945/ajcn.114.092189.

Neshatdoust S, Saunders C, Castle SM, Vauzour D, Williams C, Butler L et al. High-flavonoid intake induces cognitive improvements linked to changes in serum brain-derived neurotrophic factor: two randomized, controlled trials. Nutr Healthy Aging 2016; 24:81-93. doi:10.3233/NHA1615.

Sorond FA, Hurwitz S, Salat DH, Greve DN, Fisher ND. Neurovascular coupling, cerebral white matter integrity, and response to cocoa in older people. Neurology 2013; 81:904-9. doi:10.1212/WNL.0b013e3182a351aa

Desideri G, Kwik-Uribe C, Grassi D, Necozione S, Ghiadoni L, Mastroiacovo D et al. Benefits in cognitive function, blood pressure, and insulin resistance through cocoa flavanol consumption in elderly subjects with mild cognitive impairment: the Cocoa, Cognition, and Aging (CoCoA) Study. Hypertension 201260:794-801. doi: 10.1161/HYPERTENSIONAHA.112.193060

Crews WD, Harrison DW, Wright JW. A double-blind, placebo-controlled, randomized trial of the effects of dark chocolate and cocoa on variables associated with neuropsychological functioning 
and cardiovascular health: clinical findings from a sample of healthy, cognitively intact older adults. Am J Clin Nutr 2008;87:872-80. doi: 10.1093/ajcn/87.4.872

Tariq SH, Tumosa N, Chibnall JT, Perry III HM, and Morley JE. The Saint Louis University Mental Status (SLUMS) Examination for detecting mild cognitive impairment and dementia is more sensitive than the Mini-Mental Status Examination (MMSE) - A pilot study. Am J Geriatr Psych 2006;14:90010. doi: 10.1097/01.JGP.0000221510.33817.86

Morris JC, Heyman A, Mohs RC et al. The Consortium to Establish a Registry for Alzheimer's Disease (CERAD). Part I Clinical and neuropsychological assessment of Alzheimer's disease. Neurology 1989;39:1159-65. doi: 10.1212/wnl.39.9.1159

Lezak M, Hovieson D, Loring D. Neuropsychological assessment. 4. painos. Oxford University Press. 2004 Spreen O. Strauss E. A compendium of neuropsychological tests. 2. painos. Oxford University Press. 1998.

Robbins R, Leonczak J, Li J, Johnson J, Collins T, Kwik-Uribe C, Schmitz H. Flavanol and Procyanidin Content (by Degree of Polymerization 1-10) of Chocolate, Cocoa Liquors, Cocoa Powders, and Cocoa Extracts: First Action 2012.24. Journal of AOAC International 2013; 96(4): 705-11. doi: https://doi.org/10.5740/jaoacint.13-109

Smit HJ. Theobromine and the pharmacology of cocoa. Handb Exp Pharmacol. 2011;(200):201-34. doi: 10.1007/978-3-642-13443-2_7

Nehlig A1.The neuroprotective effects of cocoa flavanol and its influence on cognitive performance. Br J Clin Pharmacol. 2013;75(3):716-27. doi: 10.1111/j.1365-2125.2012.04378.x

White DJ, Camfield DA, Maggini S, Pipingas A, Silberstein R, Stough C, Scholey A. The effect of a single dose of multivitamin and mineral combinations with and without guaraná on functional 
brain activity during a continuous performance task. Nutr Neurosci, 2017;20(1):8-22. doi: $10.1179 / 1476830514 Y .0000000157$

Santos HO, Macedo RCO. Cocoa-induced (Theobroma cacao) effects on cardiovascular system: HDL modulation pathways. Clin Nutr ESPEN 2018;27:10-5. doi: 10.1016/j.clnesp.2018.06.001 Sotaniemi M, Pulliainen V, Hokkanen L, Pirttilä T, Hallikainen I, Soininen H \& Hänninen T. CERAD-neuropsychological battery in screening mild Alzheimer's disease. Acta Neurologica Scandinavica 2012; 125(1): 16-23. doi: 10.1111/j.1600-0404.2010.01459.x

AIVO data system for calculation of nutrient intake https://www.mashie.com/fi/palvelut/ravintolaskenta/ (13.9.2019)

Sintonen H. The 15D instrument of health-related quality of life: properties and applications. Annals of Medicine 2001:5:328-36. PMID: 11491191

Yesavage JA et al. Development and validation of a geriatric depression screening scale. J Psychiatr Res 1983; 17:37-49. PMID: 7183759

Chandler MJ, Lacritz LH, Hynan LS, Barnard HD, Allen G, Deschner M, Weiner MF, Cullum CM. A total score for the CERAD neuropsychological battery. Neurology 2005;65(1):102-6. doi: 10.1212/01.wnl.0000167607.63000.38

Hänninen T, Veijo Pulliainen V, Salo J, Hokkanen L, Erkinjuntti T, Koivisto K, Viramo P, Soininen H. Suomen Muistitutkimusyksiköiden asiantuntijaryhmä. Kognitiiviset testit muistihäiriöiden ja alkavan dementian varhaisdiagnostiikassa: CERAD-tehtäväsarja. Suomen Lääkärilehti 1999;15:1967-1975. https://www.kaypahoito.fi/sll12038 (13.9.2019)

Nordic Nutrition Recommendations 2012. Part 1. Summary. principles and use. Nord 2013:009; Copenhagen: Nordic Council of Ministers; 2013. http://dx.doi.org/10.6027/Nord2013-009 (13.9.2019) 
European Food Safety Authority (EFSA). Scientific Opinion on the substantiation of a health claim related to cocoa flavanols and maintenance of normal endothelium-dependent vasodilation pursuant to Article 13(5) of Regulation (EC) No 1924/20061 EFSA Panel on Dietetic Products. Nutrition and Allergies (NDA). EFSA Journal 2012;10:2809.

Liisa Valsta, Niina Kaartinen, Heli Tapanainen, Satu Männistö, Katri Sääksjärvi, (eds.). Ravitsemus Suomessa - FinRavinto 2017 -tutkimus [Nutrition in Finland - The National FinDiet 2017 Survey]. Institute for Health and Welfare (THL). Report 12/2018. 239 pages. Helsinki. Finland 2018. http://urn.fi/URN:ISBN:978-952-343-238-3 (13.9.2019)

Päivikki Koponen Katja Borodulin, Annamari Lundqvist, Katri Sääksjärvi ja Seppo Koskinen, toim. Health, functional capacity and welfare in Finland - FinHealth 2017 study. National Institute for Health and Welfare (THL). Report 4/2018. (abstract in English) http://urn.fi/URN:ISBN:978-952343-105-8 (13.9.2019)

Hooper L, Kay C, Abdelhamid A, Kroon PA, Cohn JS, Rimm EB, Cassidy A. Effects of chocolate, cocoa and flavan-3-ols on cardiovascular health: a systematic review and meta-analysis of randomized trials. Am J Clin Nutr 2012(3):740-51. doi: 10.3945/ajcn.111.023457

Ng TKS, Ho CSH, Tam WWS, Kua EH, Ho RCM. Decreased serum brain-derived neurotrophic factor (BDNF) levels in patients with Alzheimer's disease (AD): A systematic review and metaanalysis. Int J Mol Sci 2019;20:257. doi:10.3390/ijms20020257

Ho CS, Zhang MW, Ho RC. Optical Topography in Psychiatry: A Chip Off the Old Block or a New Look Beyond the Mind-Brain Frontiers?. Front Psychiatry. 2016;7:74. doi:10.3389/fpsyt.2016.00074

Ho CSH, HO RCM, Quek AML. Chronic Manganese Toxicity Associated with Voltage-Gated Potassium Channel Complex Antibodies in a Relapsing Neuropsychiatric Disorder. Int J Environ Res Public Health. 2018;15:783. doi:10.3390/ijerph15040783 
Ho RCM, Chua AC, Tran BX, Choo CC, Husain SF, Vu GT, McIntyre RS, Ho CHS. Factors Associated with the Risk of Developing Coronary Artery Disease in Medicated Patients with Major Depressive Disorder. Int J Environ Res Public Health. 2018;15:2073. doi:10.3390/ijerph15102073

Husain SF, Tang TB, Yu R, Tam WW, Tran B, Quek TT, Hwang SH, Chang CW, Ho CS, Ho RC. Cortical haemodynamic response measured by functional near infrared spectroscopy during a verbal fluency task in patients with major depression and borderline personality disorder. EBioMedicine 2020;51:102586. doi:10.1016/j.ebiom.2019.11.047 
439 people responded to the press release and showed interest in the study by contacting the researchers by phone, email or internet-based registration form

\begin{tabular}{|l|l|}
\hline & $\begin{array}{l}\text { After the telephone screening } 313 \\
\text { were excluded: } \\
76 \text { had a chronic illness with } \\
\text { medication } \\
35 \text { did not fulfill the other inclusion } \\
\text { criteria } \\
26 \text { refusals } \\
5 \text { with acute illness } \\
171 \text { were excluded after the power } \\
\text { calculation }\end{array}$ \\
\hline
\end{tabular}

126 person attended the baseline visit based on the telephone screening

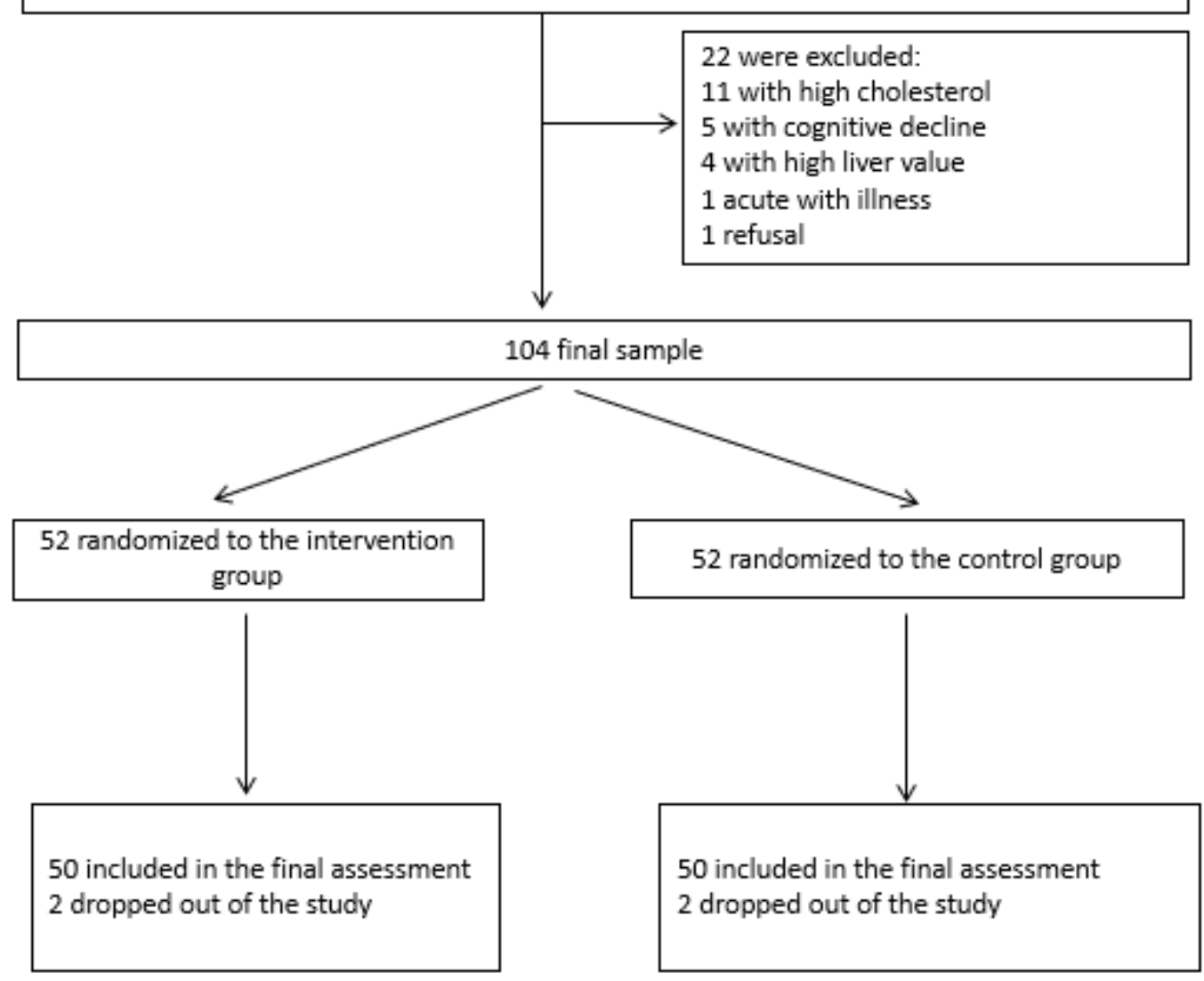




\section{Author Statement}

Dr Suominen had full access to all of the data in the study and takes responsibility for the integrity of the data and the accuracy of the data analysis.

Study concept and design: Suominen, Pitkala, Hongisto, Tuukkanen, Salmenius-Suominen Acquisition, analysis, or interpretation of data: Suominen, Jyvakorpi, Kautiainen, Pitkala, Salmenius-Suominen, Laaksonen

Drafting of the manuscript: Suominen, Laaksonen, Kautiainen, Pitkala, Tuukkanen Critical revision of the manuscript for important intellectual content: Suominen, Laaksonen, Jyvakorpi, Kautiainen, Pitkala, Salmenius-Suominen, Hongisto

Statistical analysis: Suominen, Salmenius-Suominen, Kautiainen, Pitkälä

Administrative, technical, and material support: Suominen, Pitkala, Hongisto, Tuukkanen, Salmenius-Suominen, Laaksonen

Study supervision: Suominen and Pitkala 


\section{Highlights:}

- Only few trials have studied how dark chocolate affects cognition in older adults.

- Short-term dark chocolate consumption did not show beneficial effects on cognition.

- Dark chocolate is a safe source of cocoa flavanols for healthy older adults. 